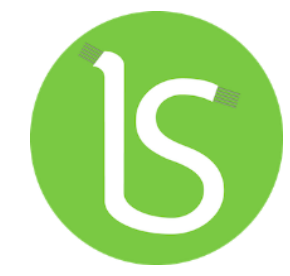

\title{
Follaje: producción y comercialización ante la nueva normalidad
}

\author{
Griselda Jacqueline Morales Alarcón a \\ Danú Alberto Fabre Platas b
}

\begin{abstract}
Resumen - Actualmente los productores y comerciantes del follaje presentan retos ocasionados por la pandemia, además de la creación de nuevas condiciones (no siempre favorables) generadas ante la nueva normalidad. Sabemos que el proceso de producción consta de varias facetas, partiendo desde la siembra pertinente hasta la venta en mercados; sin embargo, en tiempos recientes, éste se adaptó a la necesidad de un escenario antes inimaginado afectando en cada una de las fases de este. Desde la economía social la producción, distribución y venta del follaje es realizada por los habitantes de la comunidad Los Fresnos, La Perla, Veracruz; donde cada uno de ellos es importante para que la actividad económica llegue hasta su destino. La descripción analítica de ello es parte central de este artículo. Se parte del marco contextual en el territorio señalado, el proceso para el comercio del follaje y las actividades entorno a las actividades económicas realizadas en esta comunidad.
\end{abstract}

Palabras clave - Follaje, Economía Social, Producción, Comercialización, Comunidad.

Abstract - Currently, foliage producers and traders present challenges caused by the pandemic, in addition to the creation of new conditions (not always favorable) generated by the new normal. We know that the production process consists of several facets, starting from the relevant sowing to the sale in markets; However, in recent times, it has been adapted to the need for a previously unimagined scenario, affecting each of its phases. From the social economy, the production, distribution, and sale of the foliage is carried out by the inhabitants of the Los Fresnos community, La Perla, Veracruz; where each of them is important for economic activity to reach its destination. The analytical description of it is a central part of this article. It starts from the contextual framework in the indicated territory, the process for the foliage trade and the activities around the economic activities carried out in this community.

Keywords - Foliage, Social Economy, Production, Marketing, Community.

\section{CÓMO CITAR \\ HOW TO CITE:}

Morales-Alarcón, G. J., y FabrePlatas, D. A. (202I). Follaje: producción y comercialización ante la nueva normalidad. Interconectando Saberes, (12), |5|-164.

https://doi.org/I0.25009/is.v0il 2 .2714

Recibido: 16 de junio de 2021 Aceptado: 8 de julio de 2021 Publicado: 20 de julio de 2021

a Universidad Veracruzana. México. E-mail: jaquel0morales@gmail.com

b Universidad Veracruzana. México. E-mail: dfabre@uv.mx

(iD) $0000-0002-6581-1803$ 


\section{INTRODUCCIÓN}

Hoy en día se viven cambios derivados de la pandemia como; trabajar en casa, asistir a clases en línea e incluso llevar todos los productos indispensables a domicilio para no exponer a nadie. El mundo ha dado una vuelta drástica pero necesaria para el bien de la salud de todos. Por su parte, expertos en cada una de las ciencias piensan y diseñan alternativas viables para los diferentes ámbitos, pese al poco tiempo han trabajado para tratar de cubrir las necesidades de la población. Asimismo, las soluciones que la población ha proporcionado en sus actividades cotidianas, tal como es el caso para los comerciantes del follaje. Que ante las adversidades ocasionadas por el COVID-19, continúan laborando, dado que es la fuente de ingresos de la que dependen cientos de familias.

Antes de abarcar el aspecto de la problemática actual, se deriva el proceso de la comercialización del follaje antes de la pandemia y los cambios ocasionados por la crisis sanitaria a nivel global. Además de la función que desempeña el follaje en las actividades o eventos cotidianos y los puntos que se deben cumplir para su venta en los mercados. A su vez, los conocimientos que permiten a los habitantes producir de manera certera las cantidades de diferentes follajes. Sin descartar el papel que juega la economía social y en la presente actividad económica, por medio de las acciones que labora la población, además de beneficiarse no solo una persona sino toda la comunidad.

\section{ECONOMÍA SOCIAL}

En la actividad económica especificada a lo largo del presente documento podemos observar el trabajo colaborativo que realizan los habitantes, siguiendo un objetivo común verde el follaje para generar ingresos que les permitan cubrir necesidades básicas como; alimentación y vivienda. Dentro de las características de la Economía Social establece que "conforma un espacio de la realidad económica integrado por formas organizativas privadas creadas por las personas para dar respuesta a sus propias demandas sociales, a sus problemas sustantivos y a sus aspiraciones sociales" (Chaves Ávila y Monzón Campos, 2018, p. 10). Además, por "su carácter social y privado las sitúa en una lógica económica y decisional bien diferenciada de la de las empresas privadas tradicionales, basadas en la lógica del capital” (Chaves Ávila y Monzón Campos, 2018, p.10).

A partir de lo anterior, Vázquez-Barquero (2018) la define como "interpretación de los procesos de desarrollo, que considera que las necesidades de la población estarían mejor cubiertas y el éxito de las iniciativas locales garantizado cuando la población define y controla los proyectos" (p.19). Desde este sentido no existen jefes, en la actividad del follaje más bien los consideran como ayudantes importantes. Siendo un proceso donde el trabajo desempeñado por cada persona es igual. Considerando las características de la población y lo que menciona Presta (2019) como papel central de economía social y "solidaria en el sistema socio-económico capitalista, pensamos que implica el gobierno de los sujetos, pequeñas comunidades $y$ poblaciones a partir de formas de poder construidas sobre la potencia ficcional de la esperanza y el poderser" (p. 586).

Continuando Alarcón Peña (2017) se refiere a la economía social de la siguiente manera;

El individuo, en el modelo de economía social de mercado resultad protagonista de su propio desarrollo. El estado deberá respetar su individualidad interviniendo solamente en 
situaciones estructurales garantizando el respeto del principio fundamental de dignidad humana que reconoce al ser humano como responsable de su propio proyecto de vida. (p.II4).

La individualidad que caracteriza a las personas al realizar su trabajo, sin que intervengan instituciones hace significante la actividad, ya que ellos de acuerdo con sus posibilidades han logrado tener presencia en los mercados. Por otra parte, dicha actividad también tiene características de la economía verde, ya que los pobladores saben que los árboles son indispensables para la calidad del follaje y el uso de fertilizantes dañan esta. Tomando en cuenta ambos aspectos y la “implementación de un modelo de economía verde tiene por objetivo final mejorar las condiciones de vida de los más pobres y disminuir la desigualdad social, los riesgos ambientales y la escasez ecológica.

\section{EL FOLLAJE COMO ACTIVIDAD ECONÓMICA}

Antes de pasar a la descripción de la comercialización del follaje frente a la nueva normalidad, es preciso señalar el proceso que conlleva la producción y venta del follaje. Actividad económica en la que participan miembros de familia de diferentes edades, cada uno cumpliendo con lo que le compete, a manera que el follaje llegué a sus lugares de destino. En la mayoría de los casos en los mercados de flores y hortalizas de los principales mercados dentro y fuera de la entidad Veracruzana, así como en la ciudad de México. Donde va a parar gran cantidad del follaje producido y comercializado por los habitantes de Los Fresnos, La Perla, Ver. Y alrededores, actividad que data de 1980 según Santiago Cruz (20/2).
Todo comienza cuando en tiempo de agua como suele llamarse por los pobladores, época que comprende los meses de mayo hasta octubre temporada de huracanes, por lo cual se convierte en el periodo ideal para la siembra del follaje. Cabe resaltar que a lo largo de los años la población se ha apropiado de diferentes técnicas para lograr que el crecimiento y desarrollo de las plantas sea óptimo. Entre los que cabe destacar el injerto la cual "consiste en la unión íntima que se produce entre dos partes vegetales de forma tal que se origina la soldadura entre ambas, las que permanecen unidas y continúan su vida de esta manera, dependiendo una de otra” (Valentini, 2003, p. I). Dicha técnica ha sido la principal en los últimos años.

Por otra parte, la realización de viveros "constituye un conjunto de instalaciones que tienen como propósito fundamental la producción de plantas" (Guerrero, 2012, p.22). El uso de la presente técnica propiciara las características necesarias en las plantas para ser sembradas en el espacio definido para ellas, ahí crecerán y vivirán el tiempo que las circunstancias externas como clima y nutrientes lo permitan. Asimismo, realizan la técnica tradicional que consiste en cortar de manera adecuada la rama mientras se realiza una sin exagerar en profundidad ni mucho menos realizarlo encima, dado que tiene posibilidades de derrumbe con cualquier movimiento por más mínimo que este sea.

Todos los conocimientos presentados son propios de la comunidad $y$ han sido compartidos con el fin de plasmar el presente trabajo, donde se precise la importancia de la actividad del follaje y como dicha acción se han convertido por generaciones en el sustento económico de cientos de familias. Aunque, la tecnología ha reemplazado algunos aspectos, en la 
comunidad se siguen llevando a cabo algunos de manera manual tales como el trabajo, corte y transporte de los diferentes follajes. De acuerdo con la Real Academia Española (RAE) el Follaje es un "conjunto de hojas de los árboles y de otras plantas" (2020). Con diferentes colores, formas y tamaños por su parte el Follaje ornamental se describe de la siguiente manera;

Corresponde a estructuras foliares tales como ramas, hojas y frondas que se utilizan en estado verde con fines decorativos y ornamentales, principalmente, para resaltar arreglos florales que se elaboran para ocasiones especiales o para adornar grandes áreas, como lobbies de hoteles, oficinas y patios internos, así como en la confección de ramos o bouquets, debido a que producen un efecto suavizador $y$ de contraste en el arte floral. (Salinas y Cartes, 2010, p.5)

Derivado de lo anterior, los espacios donde se encuentran sembrado el follaje son dispersos convirtiendo este punto en una limitante al tener que trasportarlo por otros medios como es con los animales de carga (caballos y asnos). Sin descartar que algunas familias cuentan con siembra cerca de su casa aspecto que posible al tratarse de una comunidad, donde los espacios por familias aún son grandes en comparación con el medio urbano. En relación con el corte cuentan con herramientas que facilitan el avance a esta actividad. Por último, en el transporte, utilizan carros de carga entre varios comerciantes para disminuir los gastos, ya que se tratan de viajes de hasta 5 horas para quienes se dirigen a la capital del país.

Pasando a otro punto, se resaltan las características de los principales follajes producidos en la mencionada comunidad. Pese a que la población cultiva otros tipos de follajes, para el presente manuscrito se consideró pertinente solo abordar tres, siendo estos los más producidos y por ende los que más ingresos generan para la comunidad. Desde este sentido, dicha actividad es vista como el sustento económico para futuras generaciones y presentes, además de que es un trabajo que se realiza en grandes grupos y que lleva una serie de pasos en donde intervienen una indefinida cantidad de personas que son beneficiadas de manera económica.

Por tal motivo se considera un evento social, pero a la vez económico, ya que los habitantes por medio de distintas acciones se apoyan mutuamente, generando ingresos para sus familias $y$ aportando de esta manera a los demás habitantes de la comunidad. Las actividades van desde sembrar el follaje en las tierras destinadas para ello hasta la venta del follaje en los principales mercados de flores y hortalizas dentro de la región y la capital de México. Asimismo, el proceso en la mayoría de las ocasiones es familiar donde participan desde diferentes puntos. Siendo esto posible al pertenecer a un contexto rural en el cual las familias poseen como mínimo 5 integrantes y hasta 12 o más integrantes.

En lo que refiere al tipo de follaje es un tiempo distinto para cosecharlo, el cual comprende desde el siguiente año hasta dos años después. Todo dependerá de las condiciones del espacio, así como las condiciones climatológicas del año. Desde este punto con el cambio climático que actualmente existe en la tierra a provocado que la calidad del follaje sea inferior, según los habitantes que se han dedicado por más de tres décadas a esta función precisan que antes crecía muy alto en tampoco tiempo. Hoy día su crecimiento demora un poco más. A su vez es importante el follaje, ya que se deben mantener árboles que servirán como abono al 
caer sus hojas, además de pensar en el periodo del marzo y abril donde se siente el calor siendo cansado lograr contar los manojos. A comparación de la siembra de la papa o el maíz donde en los terrenos son cortados todos los árboles.

\section{Los tres principales follajes}

Comenzando con la respectiva descripción del primer tipo de follaje, el cual es denominado como clavo japones entre sus habitantes y por su nombre científico (Pittosporum tobira). Mismo que debe ser apodado o cortado, actividad que permitirá su crecimiento en abundancia hasta llegar a ser un arbusto e incluso un árbol tras largos años. Empero en este tipo de follaje

se utilizan los métodos de injerto y vivero por las características que posee, mismas que permiten sobrevivir un poco más a las condiciones que presenta su contexto. Como es el caso de la rama, suelo, propiedades, lluvia, sol, por mencionar algunas. Se empezó por describir el clavo japones, dado que actualmente es el que más actividad produce y desde luego genera más ingresos a comparación de los siguientes. Aspecto que se tratara más adelante.

En lo que refiere al tamaño de la planta, puede hasta alcanzar una altura de hasta 5 metros, por ello es importante quitarle aquellas hierbas que no le permitan crecer e inclusive podrir, esto se detona con las plantas más antiguas que existen en el territorio que tienen entre los 25- 30 años de vida. Su color es un verde oscuro y verde claro en las puntas señal que está creciendo, las ramas suelen ser atractivas y sobre todo resistentes en todo el proceso para su comercio. A lo largo de los años se ha convertido en uno de los principales follajes que cultivan los pobladores, dado el poco cuidado que necesita, así como el crecimiento que tiene en poco tiempo a diferencia de los demás. Aunque dicha situación no descarta la importancia de los dos tipos de follaje restantes que se describen en los siguientes párrafos.

Como segundo punto tenemos el clavo normal o limonaria ambos nombres empleados para ubicar este tipo de follaje y por su nombre científico (Choysia Ternata), follaje que a pesar de requerir un cuidado mayor que el anterior permanece su cultivo y comercio. El proceso para córtalo es difícil al ser las ramas más delgadas y al convertirse en un arbusto pequeño, la persona que lo corta debe agacharse constantemente. Hasta lograr obtener el manojo, mismo que de acuerdo con la experiencia de las personas conocen la cantidad exacta de varas que debe contener. En lo que refiere a su tamaño, aunque puede alcanzar el metro y medio por muy alto e inclusive un poco más, no resulta muy atractivo que sea más grande, además que las varas se convierten más grueso y pierde credibilidad y la distinción que los caracteriza.

Por consiguiente, las hojas que posee la planta lo hacen idóneo para estar inmerso en los distintos arreglos florales que realizan las personas, además del color y olor que desprende, lo hace único. Su tiempo de vida es de una semana con las condiciones apropiadas. Es relevante apuntar que la escasez del follaje en los meses de marzo abril provocan que su precio aumente en el mercado, ofreciendo mejores beneficios económicos a los pobladores. Está acción obedece a criterios de la economía como es el caso de; "el precio dependerá de las variaciones en los costos de producción y de ventas, así como de las políticas de margen de ganancias de las empresas y de las estrategias de expansión de la firma” (Huerta Quintanilla, 2016, p.37.) 
Como tercer punto y no menos importante se encuentra la Tulia (Thuja occidentalis), aquel tipo de follaje que requiere más cuidados, además su crecimiento es lento y su venta es menor a diferencia de los dos anteriormente descritos, ante tales circunstancias los habitantes optan por ocupar los espacios utilizados en los demás follajes e inclusive llegan a arrancar estas plantas. Es importante señalar que el tipo estimado para poder cortar y vender esta planta va desde los 3 años, lo cual ocasionan que las personas no tengan ingresos económicos de esta planta durante este tiempo. Asimismo, el tiempo de retoño es lento, empero las personas que ya lo tenía lo siguen manteniendo pese a las circunstancias actuales tanto de precio como tiempo que requiere. Dado que las personas aún lo siguen utilizando por el tamaño que este posee.

Cabe mencionar, que la mayoría de las personas opta por sembrar los tres tipos de follaje en un mismo terreno, sin que esto afecte a los demás. Para dicho ejercicio se acomodan los surcos que son espacios posibles que deberá de tener cuando alcance su máxima altura y ancho, esta técnica puede ser utilizada de manera vertical u horizontal según las condiciones del sitio con el que cuente la persona o de acuerdo con sus posibilidades. A su vez, la decisión de tener los tres tipos de follajes o hasta más se debe a que con el uso de las tecnologías las personas pueden comunicarse que necesitan algún follaje y lo puedan cortar sin tener la necesidad de buscarlo en otro lugar. Aspecto que ocasionaría costos y por ende las ganancias serían menores.

\section{Siembra}

A lo largo de los años los saberes para la siembra se han trasmitido de generación en generación. El proceso es el siguiente; las personas cortan el follaje en el tallo de una manera sesgada, la cual se debe de humedecer antes de sembrarla. Ante tal punto, se realiza un hoyo en la tierra mismo que no deberá ser profundo ni por encima, dado que la primera opción haría que la planta se seque, ya que por el exceso de agua que pudiese haber se podriría o por otra parte se secaría al no tener la suficiente cantidad de agua. Una vez que se coloca la planta en la excavación se coloca la tierra nuevamente, sin presionar demasiado para que el agua se filtre, además sin dejar la tierra débil, ya que un simple movimiento del viento o el paso de personas y animales podrías ocasionar que se desprende fácilmente.

Otro aspecto por considerar es el tiempo idóneo que contemplan los habitantes para la siembra el cual es desde mayo cuando empiezan las lluvias hasta el I5 de julio fecha cuando inicia la canícula, periodo que se caracteriza por calores intensos. Ante ello se opta por trabajar el espacio que será ocupado para sembrar las plantas, ya que la hierba puede secarse lo necesario para posteriormente colocarla entre surcos y servir como abono para las plantas. El periodo de canícula termina el 20 de agosto a partir de esta fecha y hasta mediados de octubre se ocupa para sembrar las plantas, ya que el clima es el indicado para sembrar o resiembra actividad que consiste en quitar las plantas secas 0 podridas por nuevas, a manera de no desperdiciar ningún espacio para dicha actividad y mantener los sucos horizontales o verticales según el terreno. 


\section{Trabajo y corte del follaje}

Para trabajar los tres tipos de follaje se utiliza el azadón y manos para quitar aquellas hierbas que se encuentra muy cerca de las plantas y que son imposible quitarlas con el azadón. En algún momento derivado por el pago a los campesinos y del follaje se optó por utilizar químicos que terminaran con la hierba. Aunque la mayoría de las personas dejó esta opción dado que el follaje se quemaba y quemar aquella hierba que sirve como abono para las plantas generaba que el follaje no fuera de buena calidad, además las hojas se ponían amarillas para finalmente caerse. Además del daño que ocasionaba a las plantas que estaba en el espacio tanto follaje como flores y árboles, el suelo era de los más afectados, ya que en ocasiones el mismo químico era infiltrado y se quedaba en el suelo, provocando la perdida de lo que estaba a su alrededor.

Con referencia a lo anterior, el trabajo de las plantas no solo consiste en quitar la hierba, en este tipo de trabajo se debe cuidar que al desprender la planta esta no tenga demasiada tierra, es decir, evitar excavar, ya que esto provocara erosión en el suelo y posibles deslaves. Y para el caso de las plantas del follaje perfora alguna raíz al grado de ocasionar que se seque. Frecuentemente el pago por este trabajo ronda de 150 a 200 pesos por tarea cantidad que consiste en $\mathbf{6 2 8 . 8 6}$ metros cuadrados, el pago dependerá de los inconvenientes para el trabajo como; tamaño de las hierbas, sí el terreno se encuentra cuesta abajo o sí hay piedras. Por la cantidad que deben de trabajar, en la mayoría de las ocasiones optan porque todos los miembros de familia apoyen en esta labor.

En relación con el corte del follaje, este se corta con tijeras adecuadas rama por rama hasta obtener un manojo, la medida ya está clasificada por los pobladores, pero en caso de existir un inconveniente el comerciante él hace saber a las personas que cumplen dicha actividad. Para sujetas las ramas las personas utilizan una planta conocida como izote (Yucca elephantipes), a manera de presionar el tallo y no las hojas, de esta forma las hojas de follaje lucieran y estarán en buenas condiciones para ser utilizadas en arreglos florales. Sobre la cantidad del follaje los habitantes utilizan la medida de docena.

Por otra parte, existe un periodo de escasez conocido como follaje tierno que consiste en ramas de color verde claro en su totalidad, cuando debería ser un verde oscuro. Esto es apreciable a la hora de córtalo y ver que se desmaya horas después. Por tal motivo la presente etapa es complicada, ya que al no satisfacer la demanda del producto los precios se elevan y los camiones donde es trasportado a penas se observa que llevan follaje. Por el contrario, existe otro periodo de obstáculos para las personas que se dedica a dicha actividad, se trata cuando hay en abundancia, periodo que comprende agosto-septiembre. Al no haber un eventos social o religioso que requiera de arreglos florarles las ventas son mínimas. Hasta llegan casos extremos donde las personas regresan con el follaje a la comunidad para tirarlo.

\section{Trasporte}

Pasando a otro punto, es toda una travesía que realizan las personas, comenzando desde la siembra, el trabajo con el azadón para quitar aquellas hierbas mismas que producen que en ciertas ocasiones se humedezca demasiado o se seque. Córtalo mientras lo van manojeando y como son poblados rurales las personas lo cargan en su espalda. Otra opción es cargar un caballo o asno, que en promedio transporta de 22 a 28 docenes, ya que exceder esta cantidad provocaría que se cayera la cargar o lastime al animal. Para el caso 
de las personas va a depender de la edad y la condición física que tenga. Sin embargo, los hombres más fuertes logran cargar hasta 10 docenas sin importar la distancia que tengan que recorrer.

Una vez que el follaje está en la casa o espacio destinado, se comienza a acomodarlo ya sea en docenas, diez manojos o media docenas esta opción depende de cada persona. Esto los sujetan con hilo, algunos eligen un color distintivo para evitar que se confunda o como señal que dicho follaje le pertenece a una persona en específico. Aunque la mayoría opta por utilizar el color blanco, ya que es más económico y común. Estos son amarrados debajo de la mitad del follaje para que luzcan las hojas y no afectarlas por la presión necesaria para que permanezcan unidos hasta llegar a su destino. Normalmente las personas que venden el follaje en los mercados son los que desempeñan esta actividad. Dependido de la cantidad de follaje que comercializarán es el lapso empleado y el número de personas que realicen este trabajo.

Actualmente el creciente número de personas que comercializan el follaje ha ocasionado que las personas tengan menos ventas a comparación de hace 30 años, lo que también ha provocado que la población principalmente masculina emigre a los Estados Unidos con el propósito de dar las mejores condiciones a su familia. Aunque también existen otros aspectos que orillan a las personas a emigrar tal como lo describe Gordillo y Plassot (2017). En los años recientes se han observado razones adicionales a las estrictamente económicas que empujan a migrar como lo son los impactos ecológicos, los problemas de violencia o las aspiraciones a la reunificación familiar. (p.68). Otra parte de la población se traslada por ciertas temporadas al estado de Sonora para el cultivo de uva, frutas o verduras. Algunos más se dedican a realizar arreglos florales.

Prosiguiendo, el follaje es transportado en camiones a la central de abastos y mercado de JamaicaCiudad de México, Tenancingo-Estado de México, Puebla, Orizaba, Tierra Blanca, por mencionar los principales destinos. Para ser llevado, una persona o más contratan un camión con las condiciones idóneas. Se les cobra el flete por docena siendo distintos el precio ya que dependerá del espacio y peso que ocupe en el camión, también se acomoda apropiadamente a manera de estiba y cuando ya está lista lo sujetan con reatas para evitar que se quede en el camino, ya que son 4 hasta 5 horas de camino y al ir a una velocidad de 80 a 100 kilómetros por hora se tienen que evitar dichas posibilidades.

Las personas que se llevan el follaje viajan junto con el chofer por si existen imprevistos en el camino puedan actuar inmediatamente, además de esta manera llegarán junto con el follaje para empezar la venta y de alguna manera evitar que sea robado en la zona de descarga. Cabe mencionar que las personas trabajar toda la madrugada, solo podrán descansar en la tarde.

\section{Función del follaje}

La principal función de los follajes es "utilizado como relleno en los arreglos florales, colocándolos detrás de las flores con la finalidad de que contrasten y realcen el color" (Santiago Cruz, 2012, p.23). Este detalle permite que las flores se cuiden de mejor forma, evitando su maltrato cuando se tienen que llevar a un lugar en concreto. A su vez, "el cultivo de flores con fines ornamentales es una práctica antigua con mucha importancia cultural, ya que es una tradición adornar los lugares de culto religioso, festivo y doméstico. (Tlahuextl-Tlaxcalteca, Ávila-Sánchez y Leszczyñska- 
Bory, 2005, p.323). Aspecto que le da mejor vista al sitio en donde este, además hoy día es común presenciar este tipo de detalle en cualquier evento.

Otro aspecto por considerar son las partes del follaje que se utilizan en los arreglos florales que "son el tallo y las hojas que son manejados como relleno, y en este sentido resulta importante que éstas sean no muy vistosas para que la flor principal luzca en todo su esplendor (Grenón- Cascales, López-Sandoval y GarcíaPérez, 2014, p.198). Siguiendo estas palabras se debe cuidar que el objetivo principal sea el cuidado de las flores. Aunque dicho punto es realizado por las personas que se dedican a elaborar los arreglos florales de distintos tamaños además de utilizar diferentes follajes que les permiten una amplia gama de posibilidades para cada ocasión.

\section{Principales fechas de comercialización del follaje}

Las fechas importantes para comerciantes y productores del follaje son el 14 de febrero, fecha en que algunas personas acostumbran a regalar arreglos florales $\circ$ extravagantes ramos de algunas flores principalmente las rosas, tulipanes, arturio, Lillium, por mencionar algunas. Mismas que son acompañadas del follaje. Por tal motivo, los comerciantes aprovechan para comercializar más follaje. Cabe resaltar que las fechas descritas no son siempre certeras, ya que dependerá de las condiciones sociales por las que traviese el país. Para dichas festividades las personas se preparan semana $y$ media antes para cortar, transportar y acomodar el follaje. Asimismo, es un periodo donde las personas se desvelan y descartan otras actividades.

Otra festividad importante es el 10 de mayo, día de las madres. Día en que algunas personas muestran afecto a sus mamás con distintos detalles comparándolo con arreglos florales. Para cual, los habitantes de Los Fresnos empiezan a cortan, trasladan, componen y transportar el follaje desde el primero de mayo. Las personas se desempeñan por semanas tanto pequeños como adultos para obtener recursos económicos, el hecho de empezar antes a la fecha estipulada le permitirá prepararse de la mejor manera, colocando. De acuerdo con los habitantes está fecha, 14 de febrero y 12 de diciembre son en las que más se comercializa el follaje, ya que existe mayor venta a diferencia de otras fechas.

Continuando con las fechas importantes de comercialización del follaje, la siguiente es el día del padre, pese a que no se preparan con anticipación y mucho menos con grandes cantidades de follaje como las fechas anteriores es relevante para los habitantes, porque sus ventas al menos un fin de semana son mayores. Es preciso indicar que, no es porque las personas lleven en demasía de follaje a los diferentes mercados en donde ya poseen un espacio para venderlo, más bien se debe a la diferencia que existe con otros días la comercialización. La celebración del tercer domingo de junio permite que habitantes lleven a cabo el proceso desde martes hasta jueves. A su vez, en los meses de mayo y junio las ventas son estables.

En lo que refiere a la cuarta fecha se encuentra Todos Santos y Día de muertos que comprende los días I y 2 de noviembre, aunque de acuerdo con algunas tradiciones la festividad empieza desde el 28 de octubre para culminar el 2 de noviembre. Por lo que los habitantes comienzan a cortar, trasladar y transportar una semana antes como las demás festividades. Cabe resaltar que en dicha fecha lo que más se lleva a los mercados es la limonaria o clavo normal, dado que es el follaje que se coloca en los altares para los fieles difuntos, en las tumbas u otro uso que se les pueda dar 
en cada región, a su vez es la única festividad en donde el clavo japones no tiene la importancia como en las otras fechas que se han señalado previamente.

Ante tal actividad Vázquez Mantecón señala que “la imaginación de los mexicanos pobres, junto con su instinto de sobrevivencia, los llevó a llenar cada fiesta con muchos símbolos y emblemas en miniatura que vendían en esquinas, mercados y plazas (2015, p. 4). Situación que les permite a los pobladores de La Perla generar ingresos para su región desde la actividad del comercio del follaje, haciendo de una planta la función de contrastar los colores de las flores para hacerlas más atractivas. Desde este punto, el follaje a lo largo de los años se ha convertido relevante para la actividad del diseño de los arreglos florales.

Finalmente, el 12 de diciembre que se ocupa para conmemorar la aparición de la Virgen de Guadalupe en México y dado el número de católicos en el país que de acuerdo con el Instituto de Nacional de Estadística y Geografía (INEGI), 2010 representaba el $89.3 \%$ de la población mexicana. Al tener presente esta fecha en diferentes ciudades o pueblos del país los pobladores de Los Fresnos toman en cuenta esta festividad desde el primero de diciembre para preparase. Para culminar este punto, pese a que todo el año lo transportan a diferentes ciudades y mercados, no son tan importantes como las mencionadas fechas. Sin descartar algunos eventos en donde se hace uso de las flores y por ende el follaje como: bodas, quince años, bautizos, confirmaciones, comuniones, eventos sociales, graduaciones, por mencionar algunas.

\section{Costos}

Pasando a otro punto importante, el precio para cada tipo de follaje es distinto, su compra en la comunidad va de los 22 a los 25 pesos por docena para el caso de la limonaria y clavo japones y de 12 a I 5 pesos para la Tulia. Para la venta en los diferentes mercados va desde los 30 a 40 pesos, considerando el tamaño, época del año y la calidad de las hojas. También se debe de contemplar la paga del transporte, comida y las personas que ayuden para acomodar de manera apropiada el follaje. Como nos podemos percatar con la comercialización del follaje varias son las actividades que giran en torno a esta, siendo importante resaltar el papel desempeña en la economía de los habitantes.

Por consiguiente, el pago del flete es 4 pesos por docena, esta función la realizan las personas que deben de dar mantenimiento al medio de transporte para descartar lo mayor posibles accidentes automovilísticos, también el pago de las siguientes casetas; Esperanza, Amozoc, San Martín, San Marcos y viceversa. Asimismo, se debe de contratar a alguien que cumpla las funciones de acomodar el follaje en el trasporte, la cual se conocer como estibador. Por otra parte, las personas buscan fletes de regreso de preferencia a la ciudad Puebla, Orizaba o Córdoba, siendo estas cercanas a su destino. Para generar más ingresos o prever posibles gastos del transporte. Como se puede percibir el costo del follaje es inferior al de las flores lo cual es compresible ya que no necesitan tanto cuidado como la flores.

\section{Otras fuentes de ingresos entorno a la comercialización follaje}

Por otra parte, en el mismo territorio se producen flores como; Alcatraz (Zantedeschia aethiopica), agapando (Agapanthus) y hortencia (Hydrangea), mismas que son sembradas, cuidadas y comerciadas a los mercados mencionados anteriormente. Empero, no se hizo énfasis en estas porque tienen una producción inferior al follaje, además se tiene que dedicar más esfuerzos en ellas, espacio 
entre otros puntos más. Aunque no menos importante, dado que generan ingresos para la población. Aunque los habitantes que poseen más de 60 años señalan que el clima no es el mismo por lo cual la producción del alcatraz ha disminuido severamente, plasmando que antes se presenciaban más fríos.

En lo que concierne al Agapando se ha dejado de cultivarlo en grandes proporciones por el precio que tiene en los mercados y para el caso de la hortensia, se destinan más espacios para esta flor a comparación de las demás. Existen varios colores, pero los principales dentro de la comunidad son el verde, morado, azul y la combinación de estos dos últimos. También esta flor no daña los tres tipos de follaje, aspecto que si logra hace el alcatraz y apagando por las hojas resbalosas que tiene. Cada persona organiza la tierra que posea para un solo follaje o para todos los descritos anteriormente, solo es cuestión que deje un espacio entre las plantas.

\section{Economía desde diferentes actividades en torno al follaje}

Una vez descrita la función económica que cumple el follaje para los habitantes de la localidad perteneciente al municipio de La Perla en el estado de Veracruz. Se describe el empleo que proporciona a los habitantes desde diferentes actividades. Comenzando con aquellos que cultivan el follaje, los cuales venden estas plantas, en algunas ocasiones se les paga a personas para que trabajen con azadón, las que cortan posteriormente aquellos que lo componen para que sea transportando, luego aquellos que organizan los fletes, las personas que estiban, $y$ finalmente las que venden el follaje en los mercados. En la zona de Flores y hortalizas.

Desde esta perspectiva es una actividad que ha generado ingresos a las familias $y$ ha mantenido a numerosas familias. En el presente solo se rescató de una comunidad en particular, pero dicha actividad es realizada por varias comunidades del municipio e inclusive en otros municipios como Mariano Escobedo y Coscomatepec. Donde también se pueden presenciar grandes cultivos del Follaje específicamente de los que se describieron. E incluso de otros municipios como Córdoba el camedor, gracenia y maicera. Otros tipos de follajes que por las condiciones climatológicas no es posible cultivarlas en la localidad.

\section{La comercialización del follaje frente a la nueva normalidad}

Ante la propagación del virus SARS-Cov-2 por el mundo, los expertos en el campo de la salud diseñaron varias medidas para evitar el contagio. Como las que señala López-Ortiz, et al. (2020) Precauciones estándar, precauciones de transmisión por gotas y precauciones de transmisión por aerosoles (p.l36). Además, una vez ubicado el país en semáforo rojo las medidas fueron más exigentes como; cierre de panteones u otros establecimientos. Asimismo, la suspensión de eventos sociales para evitar aglomeraciones, para el caso de los mercados como la Central de Abastos continúo trabajando con las medidas pertinentes.

No obstante, la necesidad por adquirir bienes comestibles ocasiono que las ventas del follaje disminuyeran. Tomando en cuenta que México declara estado de emergencia sanitaria el 30 de marzo del presente año, y considera relevantes los siguientes establecimientos mediante el Consejo de Salubridad General (CSG) 2020;

Financieros, el de recaudación tributaria, distribución y venta de energéticos, gasolineras y gas, generación y distribución de agua potable, industria de alimentos y bebidas no alcohólicas, 
mercados de alimentos, supermercados, tiendas de autoservicio, abarrotes y venta de alimentos preparados; servicios de transportes de pasajeros y carga; producción agrícola, pesquera y pecuaria, agroindustria, química, productos de limpieza; ferreterías, servicios de mensajería, guardias en labores de seguridad privada; guarderías y estancias infantiles, asilos y estancias para personas de la tercera edad, refugios y centros de atención a mujeres víctimas de violencia, sus hijas e hijos; telecomunicaciones y medios de información, servicios privados de emergencia, servicios funerarios y de inhumación, de almacenamiento y cadena de frío de insumos esenciales, logística (aeropuertos, puertos y ferrocarriles), así como actividades cuya suspensión pueda tener efectos irreversibles para su continuación (p.5).

Todos los lugares mencionados obedecen a las necesidades primordiales del hombre, $y$ el follaje es requerido para la venta de arreglos florales por tal motivo se descarta. Por ello la producción del follaje en las siguientes fechas; 10 de mayo, día del padre, graduaciones y día de muertos fueron escasas, además de que los panteones $y$ las reuniones familiares continúan restringidas. Ante tal actitud los comerciantes del follaje toman en cuenta el uso de la tecnología para estar en contacto con las personas que les venden el follaje. Esta situación permitió a ambas partes una constante comunicación a la vez que se toma en cuenta las exigencias del comprador. Es decir, las características que necesita del follaje.

Empero, para las generaciones actuales el uso de dispositivos móviles no fue inconveniente alguno, ya que el uso de las redes sociales como WhatsApp o Facebook son parte de su vida. El inconveniente surgió en las personas mayores y la inexistencia de cobertura de internet y móvil en las comunidades rurales. De acuerdo con la Encuesta Nacional Sobre Disponibilidad y Uso de Tecnologías de la Información en los Hogares (ENDUTIH) 2017, había un total de 1.3 millones de usuarios de Internet y $\mathbf{1 7 . 4}$ millones de hogares con conexión a internet. Mientras la disposición de computadoras 45.4 millones.

Desde este sentido el comercio del follaje se sigue dando a pesar de las circunstancias, ya que es la única fuente de ingresos para dicho poblado. Mientras la población continúe obsequiando flores en cumpleaños, aniversarios, eventos importantes, exámenes de grados, aunque se realicen de manera virtual, gusto por tener arreglos florales en casa, entre otros más. La población de la comunidad de Los Fresnos continuará produciendo y comercializando los diferentes follajes a distintos mercados del País con las medidas que instituciones gubernamentales les indiquen, entre las más comunes el uso de cubrebocas y gel antibacterial, lavado frecuente de manos y mantener la sana distancia.

\section{CONCLUSIÓN}

A lo largo del presente manuscrito se abordó el proceso necesario para la venta del follaje, las diferentes actividades que giran en torno a dicha actividad económica. $Y$ el papel relevante entre los involucrados para que se realicen de manera certera los pasos a seguir, sin descartar el conocimiento necesario para obtener como resultado su venta en los mercados, siendo este el principal objetivo. Así, como los inconvenientes generados en el trascurso de la pandemia sobre el proceso de comercialización. La importancia del seguimiento de las medidas sanitarias 
por parte de las autoridades para continuar laborando y otras obligaciones que debe de tomar en cuenta el productor del follaje.

Por otra parte, la situación alerta una crisis a nivel mundial que afectará o está afectando a varios grupos de personas, entre ellos los comerciantes, ya que son personas que sí no existen ventas, no generan ingresos a diferencia de los trabajadores de gobierno mismo que se les permite trabajar por vía remota. Para este tipo de personas la situación es diferente, sin importar las condiciones deben continuar laborando todo el año. Sí bien actualmente algunos establecimientos están manejando él envió a domicilio, este ejemplo nos aplicaría, ya que los mercados son puntos de encuentro, donde los dueños de florerías o establecimientos a fines de varios estados, para el caso de la central de abastos toman como punto de encuentro la capital, pensar en esta solución solo generaría más gastos.

De acuerdo con el Programa de las Naciones Unidas para el Desarrollo (PNUD) "se estima que la crisis económica por la COVID-19 sea la más intensa desde el final de la Segunda Guerra Mundial”. (2020, P. 6). Situación comprensible por el cierre de todas las empresas, industrias, escuelas, prácticamente de todo. Situación que también propició el alza de los precios de la canasta básica. En contraste el CONEVAL (Consejo Nacional de Evaluación de la Política de Desarrollo Social) “calcula 9,310,153 personas en situación de pobreza extrema, lo que implica que, entre otras carencias, aun destinando todo su ingreso a la adquisición de alimentos, no pueden adquirir lo indispensable para tener una nutrición adecuada" (PNUD, 2020, p.26).

\section{BiBLIOGRAFÍA}

Alarcón Peña, A. (20I8). Origen y Características del Modelo de la Economía Social de Mercado.

Principia luris, I4(27), 98-1 I7. https://www.mendeley.com/catalogue/c65 I8622a576-33c7-a65I-I5I25flee7cd/

Chaves, R. y Monzón, J.L. (2018). La economía social ante los paradigmas económicos emergentes: innovación social, economía colaborativa, economía circular, responsabilidad social empresarial, economía del bien común, empresa social y economía solidaria, CIRIEC-España, Economía Pública, Social y Cooperativa, 93, 5-50, https://doi.org// 0.7203/CIRIEC-E.93.I290 I

Consejo de Salubridad General. (30 de marzo de 2020). Medidas de Seguridad Sanitaria.

Gordillo, G., y Plassot, T. (20I7). Migraciones internas: un análisis espacio-temporal del periodo 197020I5. ECONOMÍA UNAM, I4(40), 67-I00.

Grenón Cascales, G. N., López-Sandoval, J. A., y Diana, G. P. (20I4). Follajes comercializados en dos mercados de flores del altiplano central mexicano. Polibotánica (38), 193- 212. http://www.scielo.org.mx/scielo.php?script=sci_a rttext\&pid=SI 405-276820 I40002000 I I

Guerrero Guerrero M. L. (20I2). El vivero de plantas nativas, un elemento clave en el manejo integral de la microcuenca la Goya. (Tesis para obtener el grado de maestría en Gestión Integrada de Cuencas) Santiago de Querétaro: Universidad Autónoma de Querétaro. http://ring.uaq.mx/handle// 23456789/748

Huerta Quintanilla, R. (20I6). Brevísimo curso de microeconomía. Ciencia Económica, 5(8), enerojunio, Pp. 25-52.

http://www.economia.unam.mx/cienciaeco/pdfs/n um8/03HUERTA.pdf

Instituto Federal de Telecomunicaciones. (20I8). Encuesta Nacional sobre Disponibilidad y Uso de Tecnologías de la Información en los Hogares (ENDUTIH). http://www.ift.org.mx/comunicaciony-medios/comunicados-ift/es/en-mexico-7/3millones-de-usuarios-de-internet-y-I74-millonesde-hogares-con-conexion-este-servicio

Instituto Nacional de Estadística y Geografía. (2 de noviembre de 2020). Población - Religión. Censos y Conteos de Población y Vivienda. https://www.inegi.org.mx/temas/religion/ 
López-Ortiz, E., López-Ortiz, G., Mendiola-Pastrana, I. R., Mazón-Ramírez, J. J., y Díaz-Quiñonez, J. A. (2020). De la atención de un brote por un patógeno desconocido en Wuhan hasta la preparación y respuesta ante la emergencia de Covid-1 9 en México. Gaceta médica de México, I56(2), I33-138.

Martínez, A., y Porcelli, A. (20I7). Reflexiones sobre la economía verde. El New Deal Ecológico Mundial. LEX, I5(I9), 36I.

http://dx.doi.org//0.2I503/lex.v15il9.1383

Presta, S.R. (2019). Trabajo, economía social y solidaria y nuevas tendencias tecnológicas. Trabajo y Sociedad, 32, 567-589.

https://dialnet.unirioja.es/servlet/articulo?codigo= $\underline{6856135}$

Programa de las Naciones Unidas para el Desarrollo.

(2020). Desafíos de desarrollo ante la COVID-19 en México. Panorama socioeconómico. PNUD en México. Serie de Documentos de Política Pública. https://www.latinamerica.undp.org/content/rblac/ es/home/library/crisis_prevention_and_recovery Idesafios-de-desarrollo-ante-la-covid-19-enmexico--panorama-soci.html

Real Academia Española. (30 de octubre de 2020). Diccionario de la Real Academia Española. https://dle.rae.es/follaje

Salinas, M. y Cartes, F. (20I0) Resultados y Lecciones en Producción de Follaje Ornamental de Especies Nativas: Proyecto de Innovación en Regiones de Los Ríos y de Los Lagos: Flores y Follajes. Chile: Serie experiencias de innovación para el emprendimiento agrario.

http://bibliotecadigital.fia.cl/handle/20.500.I I 944/ $\underline{2073}$

Santiago Cruz, C. R. (20I2). Agricultura Capitalista dependiente y los problemas de Tecnología Agropecuaria transferencia de tecnología (CASO: Follajes ornamentales en La Perla, Veracruz). (Tesis para obtener el grado de ingeniero agrónomo especialista en sociología rural). Chapingo: Universidad Autónoma de Chapingo. http://chapingo.koha.es/cgi-bin/koha/opacdetail.

Tlahuextl-Tlaxcalteca, C., Ávila-Sánchez, J. M., y Leszczyñska-Bory, H. (2005). Flores de corte y follaje en florerías. Chapingo Serie Horticultura, I I (2), 323-327. https://www.redalyc.org/pdf/609/609 I I220.pdf

Valentini, G. (2003). La injertación en frutales. Buenos Aires: Instituto Nacional de Tecnología Agropecuaria. https://inta.gob.ar/sites/default/files/script-tmpintasp-valentinibdt |4.pdf
Vázquez Barquero, A. (2018). Reflexiones teóricas sobre la relación entre desarrollo endógeno y economía social. Economía Solidaria e Innovación Socioecológica, (I), II-22. http://rabida.uhu.es/dspace/bitstream/handle// 02 72/I5749/reflexiones teoricas.pdf?sequence $=2$

Vázquez Mantecón, M. del C. (20I5). I y 2 de noviembre en la ciudad de México, I750-1900. Estudios de Historia Moderna y Contemporánea de México, (49), I-18.

https://doi.org//0.1016/j.ehmcm.2015.05.001 